\title{
MRS authors recently elected to the US National Academy of Engineering
}

$\mathrm{T}$ he US National Academy of Engineering (NAE) has elected nine authors from the Materials Research Society (MRS), with 87 new members and 18 foreign members, bringing the total US membership to 2309 and the number of foreign members to 281 . Individuals in the newly elected class will be formally inducted during NAE's annual meeting in Washington, DC, on October 4. Election to the NAE is among the highest professional distinctions accorded to an engineer. Academy membership honors those who have made outstanding contributions to "engineering research, practice, or education, including, where appropriate, significant contributions to the engineering literature" and to "the pioneering of new and developing fields of technology, making major advancements in traditional fields of engineering, or developing/implementing innovative approaches to engineering education." A list of the newly elected MRS authors, along with their primary affiliations at the time of election and a brief statement of their principal engineering accomplishments, follows.

Founded in 1964, the NAE is a private, independent, nonprofit institution that provides engineering leadership in service. The mission of NAE is to advance the well-being of the nation by promoting a vibrant engineering profession, and by marshalling the expertise and insights of eminent engineers to provide independent advice to the federal government on matters involving engineering and technology.

The NAE has more than 2000 peerelected members and international members, senior professionals in business, academia, and government who are among the world's most accomplished engineers. They provide leadership and expertise for numerous projects focused on the relationships among engineering, technology, and the quality of life.

\section{Cangratulations Newty elected mRs authors}

\section{Horacio D. Espinosa}

James N. and Nancy J. Farley Professor in Manufacturing and Entrepreneurship, Northwestern University, USA For contributions bridging nanoscale experimentation and atomistic simulations.

\section{Chennupati Jagadish}

Distinguished Professor, Electronic Materials Engineering, Australian National University, Australia

For contributions to nanotechnology for optoelectronic devices.

\section{Sarah Kurtz}

Professor, Materials Science and Engineering,

University of California, Merced, USA

For contributions to the development of GalnP/GaAs photovoltaic cells and leadership in solar-cell reliability and quality.

\section{Jayathi Y. Murthy}

Ronald and Valerie Sugar Dean and Distinguished Professor, Henry Samueli School of Engineering and Applied Science, University of California, Los Angeles, USA

For the development of unstructured solution-adaptive finite volume methods for heat, mass, and momentum transport.

\section{Nancy R. Sottos}

Swanlund Endowed Chair, University of Illinois

at Urbana-Champaign, USA

For contributions to the design and applications of self-healing and multifunctional materials.

\section{Mark E. Thompson}

Professor of Chemistry and Inorganic Chemistry, University of Southern California, Los Angeles, USA For the development of highly efficient electrophosphorescent materials for organic light-emitting devices used in displays and lighting worldwide.

\section{Richard A. Vaia}

Senior Scientist, Emergent Materials Systems,

Air Force Research Laboratory, USA

For aerospace applications of polymeric nanomaterials, and for technical leadership in materials for national defense applications.

\section{Eduard Arzt}

Chief Executive Officer and Scientific Director, INM-Leibniz Institute for New Materials, Universität des Saarlandes, Germany For research on mechanical properties and development of bioinspired functional surfaces for medical adhesives and novel gripping systems.

\section{Claudia Anna-Maria Felser}

Director, Max Planck Institute for Chemical Physics of Solids, Germany

For the prediction and discovery of engineered quantum materials ranging from Heusler compounds to topological insulators. 